\title{
História e memória: origens e desenvolvimento do programa de pós-graduação em História da Universidade Federal Fluminense
}

\author{
History and memory: origins and development of the postgraduate \\ program of History at the Fluminense Federal University
}

\author{
Francisco Falcon \\ prof@franciscofalcon.com.br \\ Professor titular \\ Universidade Salgado de Oliveira \\ Rua Marechal Deodoro, 263, bl. B, 30 andar - Centro \\ 24030-060 - Niterói - RJ \\ Brasil
}

\section{Resumo}

A convite da revista História da Historiografia, Francisco José Calazans Falcon* elaborou esta narrativa sobre o desenvolvimento do programa de pós-graduação em história da Universidade Federal Fluminense (UFF). Conjugando história e memória, este exercício de contextualização foi desenvolvido por um profissional que colaborou na criação de diversos programas de pós-graduação no Rio de Janeiro, uma parte significativa do processo de construção da pós-graduação em história no Brasil.

\section{Palavras-chave}

História da educação; Pós-graduação; Memória.

\section{Abstract}

At the invitation of the journal História da Historiografia, Francisco José Calazans Falcon** prepared this narrative about the development of the Postgraduate History course at the Fluminense Federal University (UFF). Combining history and memory, this exercise of contextualization was developed by a professional who collaborated in the creation of several postgraduate courses in Rio de Janeiro and played a significant role in the process of constructing the postgraduate field of history in Brazil.

\section{Keywords}

History of education; Postgraduate; Cultural memory.

Recebido em: 12/2/2013

Aprovado em: 10/3/2013

\footnotetext{
* Professor titular e emérito da Universidade Federal Fluminense (1955-1990), onde também atuou como pró-reitor de pesquisa e pós-graduação; professor adjunto da Universidade Federal do Rio de Janeiro (19561995) e da Pontifícia Universidade Católica do Rio de Janeiro (1958-2004).

** Emeritus professor at the Fluminense Federal University (1955-1990), where he also served as dean of research and graduate studies; associate professor at the Federal University of Rio de Janeiro (1956-1995) and at the Pontifical Catholic University of Rio de Janeiro (1958-2004).
} 
Tal como fizemos na elaboração dos textos sobre a história da pós-graduação em história no IFCS/UFRJ (FALCON 2012) e no Departamento de História da PUC-Rio, associamos também aqui história e memória para a construção da estrutura narrativa. A memória refere-se às lembranças de fatos e vivências acadêmicas variadas, já a história tem a ver com ideias e práticas vinculadas à vida universitária em geral e ao curso de história, em particular o da Universidade Federal Fluminense (UFF).

Dividimos o presente texto em duas partes principais: a primeira, mais geral, aborda explicitações conceituais e aspectos contextuais típicos dos anos que antecederam a institucionalização dos cursos de pós-graduação, nos começos dos anos 70 do século passado. Trata-se assim de tentar voltar aos anos 50 e 60 do século XX e tentar perceber aí as forças sociais em presença, os interesses em jogo, as grandes questões então em debate, mas sempre, é claro, do ponto de vista da universidade brasileira em geral e dos cursos de história especificamente: natureza dos cursos de graduação, principais tendências historiográficas, caminhos, enfim, do ensino e da escrita da História.

A segunda parte, bem mais longa, apresenta-se como a tentativa de produzir uma narrativa ora mais factual, ora mais interpretativa, das questões principais que marcaram a construção teórico-prática da pós-graduação, quer em nível nacional, quer, principalmente, no âmbito do Departamento de História da Universidade Federal Fluminense, tendo como referência principal a nossa experiência como participante desse processo.

\section{Questões preliminares: conceitos, contextos e história}

As palavras e os conceitos

Palavras e expressões como história, historiografia, historiador, obras de história, entre outras, serão constantemente utilizadas ao longo deste trabalho. Trata-se de conceitos que se encontram no bojo de questões teórico-metodológicas cuja discussão não pretendemos retomar aqui. Para as necessidades atuais de nosso trabalho, basta que se tenham em vista os conceitos tal como pretendemos utilizá-los aqui:

História significa tanto a "história matéria", ou "realidade histórica", isto é, o conjunto de fatos passados, ou res gestae, quanto a "história disciplina", ou narrativa histórica, a chamada historia rerum gestarum, ou seja, o resultado do trabalho do historiador, o texto por ele produzido (VILAR 1980).

Historiografia é uma palavra a qual correspondem, ainda hoje, múltiplos significados ao longo do tempo, especialmente: "conjunto ou sequência de obras de história" sobre determinado tema ou época histórica, ou "processo de produção do discurso histórico, inclusive o texto daí resultante, isto é, a obra de história". Persiste ainda, em alguns casos, uma certa confusão entre o que são as obras de história e o que se denomina de fontes documentais, como é o caso da historiografia do período colonial. No presente texto iremos utilizar esses dois sentidos de historiografia, explicitando-os em cada caso (ARÓSTEGUI 2006; IGLESIAS 1972; 2000). 
Historiador é para nós o profissional de história, destacando-se aqui a sua formação (graduação e pós-graduação) em história, embora consideremos como elemento decisivo o reconhecimento de seus trabalhos como de história pela comunidade historiadora. Existe aqui portanto uma certa ambiguidade quanto à própria definição de historiador, fato este que já discutimos há muito tempo atrás num trabalho sobre "A identidade do historiador" (FALCON 1996).

Obras de história - assim intitulamos livros, capítulos, artigos, comunicações reconhecidos como obras ou trabalhos de história pela comunidade de historiadores. Interessam-nos principalmente, aqui, as condições de produção de trabalhos acadêmicos associados aos cursos de pós-graduação em história: dissertações de mestrado e teses de doutorado.

\section{Tempo(s) e periodização}

Para os nossos objetivos atuais, não precisamos retomar antigas discussões sobre a periodização da historiografia brasileira (FALCON 2011; IGLÉSIAS 2000), nem, é claro, as questões sobre as relações entre tempo e história. Basta-nos levar em consideração os anos anteriores e aqueles posteriores às mudanças introduzidas na universidade brasileira em 1968/1969.

De fato, em função da temática deste trabalho, é inevitável situar em primeiro plano as diferenças de toda ordem entre as décadas de 50 e 60 do século XX e aquelas que vieram após, a partir de 1970. Embora a contragosto, somos obrigados a aceitar como um dado fundamental a chamada institucionalização dos cursos de pós-graduação no final dos anos 1960 (FALCON 2011, p. 20-23; 2008, p. 45-40). ${ }^{1}$ A partir daí, será a própria dinâmica de cada Programa que nos servirá de guia, ou seja, no nosso caso atual, a dinâmica do Departamento de História da UFF.

Contexto e história: os anos de 1950 e 1960

Do final da década de 1950 ao início da década de 1960, as transformações históricas da sociedade brasileira fizeram-se sentir na vida universitária, inclusive, é claro, no campo do ensino da história e da produção historiográfica. Operando como divisor de águas, março de 1964 estabelece uma separação nítida entre duas épocas distintas: antes e após o golpe militar. Em termos mais amplos, este período corresponde, antes de 1964, aos governos de Juscelino Kubitschek, Jânio Quadros e João Goulart, e, após, aos governos militares.

Antes, vivenciamos o desenvolvimentismo, a crise da renúncia de Jânio Quadros e os movimentos a favor de reformas estruturais, a começar pelas reformas de base, e também da reforma universitária. Depois, vieram os anos de repressão, cerceamento das liberdades, reformas por decreto e, por último, os anos de chumbo e suas sequelas. No âmbito acadêmico, universitário sobretudo, tivemos, conforme já analisamos em outros trabalhos (FALCON 2012a): o dualismo teórico-interpretativo consubstanciado na conhecida obra 
de Jacques Lambert, Os dois Brasis, o dualismo historiográfico e o acadêmico-estudantil, focados nas críticas a uma escrita e um ensino de história, sobretudo a do Brasil, eminentemente tradicionais, ou positivistas (factualistas), como era comum então denominá-los. Interessam ao nosso estudo, principalmente, o movimento estudantil em geral e especialmente nos cursos de graduação em história, e o movimento dos docentes de história, a partir da fundação da ANPUH, em 1961 (FALCON 2000; 2011).

Após o golpe militar de março de 1964 arrefeceu-se o movimento dos docentes de história e foi praticamente liquidado o movimento dos estudantes de história. Por outro lado, após algum tempo, reiniciou-se a luta dos estudantes universitários pela reforma da universidade, assim como a contestação ao regime militar. Perseguições a muitos docentes e estudantes, caçada aos livros e revistas subversivos, marcaram a radicalização das posições docentes e intelectuais assim como sua polarização.

Ganharam força autores e ideias genericamente marxistas, ao mesmo tempo em que perdia credibilidade o dualismo teórico-interpretativo em favor de novas interpretações da realidade brasileira baseadas na chamada teoria da dependência e nas noções de desenvolvimento e subdesenvolvimento. Novidade desses anos, no campo historiográfico, foi certamente a rápida expansão da chamada história quantitativa, carro-chefe das andanças de F. Mauro entre nós (LAPA 1976, p. 13-96), apesar das muitas restrições e críticas de historiadores marxistas a essa nova tendência. Também durante esses anos, 1964/1968, foram publicados, em começos de 1964, os primeiros volumes da chamada História nova do Brasil, dirigida por Nelson Werneck Sodré, e o volume Brasil em perspectiva, organizado por Carlos Guilherme Mota, em 1968, respectivamente no Rio de Janeiro e em São Paulo.

\section{a) Os caminhos da produção historiográfica}

Trata-se de uma produção historiográfica ainda bastante limitada em termos de autores e obras, conforme assinala Iglésias (IGLÉSIAS 2000, p. 213 et seq.), destacando-se apenas Nelson Werneck Sodré, José Honório Rodrigues, Sergio Buarque de Holanda, Raimundo Faoro, Helio Vianna, Pedro Calmon, além de mais alguns outros historiadores radicados em São Paulo, Porto Alegre, Curitiba, Salvador, Recife e Belo Horizonte. Os referenciais teórico-metodológicos desses autores variam bastante, embora em sua maioria possam ser definidos como do tipo tradicional, qualquer que seja o sentido que possamos atribuir a tal designação. "Lugar" por excelência de produção historiográfica já o era então a Universidade de São Paulo. Outros "lugares institucionais" eram então a Biblioteca Nacional, o Arquivo Nacional, o Instituto Rio Branco, a Casa de Rui Barbosa, o Instituto Histórico e Geográfico Brasileiro, todos no Rio de Janeiro, além de diversas instituições equivalentes situadas nos principais estados da federação. No Rio de Janeiro havia também o ISEB, uma instituição política e ideologicamente das mais polêmicas e que seria extinta após o golpe militar de 1964; a Fundação Getúlio Vargas, com seus diversos institutos, e onde se funda, ainda nos anos 1960, o CPDOC; o IUPERJ, fundado em 1964, dedicado aos 
estudos de Ciência Política e Sociologia Política mas com intensas relações com as questões históricas. Cabe não esquecer, finalmente, a importância que teve a criação do CEBRAP, em São Paulo, depois de 1964, assim como o significado especial para os historiadores que teve a fundação da ANPUH, em Marília, em fins de 1961.

\section{Uma pré-história da pós-graduação: a reforma universitária e a institucionalização da pós-graduação - dois debates interligados}

\section{a) A questão da reforma universitária}

Deixemos de lado, ao menos por ora, os marcos já bastante conhecidos que assinalam a luta em favor da construção de uma autêntica universidade no Brasil. ${ }^{2}$ Recorde-se apenas que, ao longo dos anos 1950, sobretudo à época do desenvolvimentismo de $\mathrm{JK}$, registram-se várias iniciativas voltadas para a fundação de institutos autônomos de pesquisa, como forma de desenvolver uma atividade até então pouco comum no âmbito das universidades então existentes. Os grandes debates dessa época estiveram voltados para a discussão da nova Lei de Diretrizes e Bases da Educação Nacional, a qual viria a estabelecer a oferta de cursos de pós-graduação nos estabelecimentos de ensino superior, e para o planejamento de uma nova universidade - a Universidade de Brasília. Nesta, aliás, a pós-graduação é uma das principais atribuições dos Institutos Centrais e das Faculdades Profissionais (PAOLI 1985, p. 12-15).

Em 1967, dois decretos-leis instituíram o sistema departamental nas universidades federais: Decreto-Lei número 53, de 18 de novembro de 1966, complementado pelo Decreto-Lei 252 de 28 de fevereiro de 1967. Tratava-se, a bem dizer, do início da reforma das universidades federais. A seguir, o governo criou o Grupo de Trabalho para a Reforma Universitária, em 2 de julho de 1968, o qual rapidamente encaminhou suas conclusões e sugestões, de tal forma que já em 28 de novembro de 1968 a Lei 5540 estabelecia em seus vários aspectos a reforma universitária. Em 11 de fevereiro de 1969, o Decreto-Lei 464 estabeleceu as normas complementares.

De fato, a legislação agora aprovada parecia tentar responder ou levar em conta as grandes questões do debate que tinha se desenrolado até então, como no caso, por exemplo, da extinção da cátedra vitalícia. Na verdade, porém, a forma era autoritária e o conteúdo distinto das principais propostas então em discussão. A autonomia universitária, por exemplo, cantada em prosa e verso, é parte de uma grande ilusão: as universidades teriam liberdade para empreender sua reforma, desde que se mantivessem dentro das prescrições e limites legais. A Cátedra se foi, mas em compensação criou-se uma estranha dicotomia entre o Departamento e o Curso: o Departamento reúne os docentes de uma mesma

\footnotetext{
2 "A ideia de pós-graduação como tarefa normal e permanente da universidade, constituindo sistema de cursos regulares que visam o aprofundamento da formação recebida na graduação e conduzem a graus acadêmicos, foi objetivada pela primeira vez no Brasil, no projeto da Universidade de Brasília. Esse tipo de pós-graduação corresponde à própria concepção da nova universidade, projetada nas mesmas bases dos centros de ensino e de pesquisa que estão revolucionando o mundo moderno" (SUCUPIRA apud BASTOS 1980, p. 9-10).
} 
disciplina ou área do conhecimento; o Curso é o conjunto de docentes envolvidos na composição de determinado currículo/conjunto de disciplinas.

Não cabe nesta oportunidade retomarmos a questão da análise crítica dessa reforma universitária, algo que tentamos fazer em outros trabalhos. É suficiente lembrar que, em 1968/1969, fechou-se o círculo de giz. Não haveria mais lugar para movimentos docentes ou discentes, para discussões do tipo "a universidade que temos e a universidade que queremos", e tudo que se podia fazer era adaptar estatutos e regimentos à nova legislação. Esta, aliás, tentou incorporar várias das questões que há muito eram discutidas, mas o fez de maneira deturpada, a começar pelo fato de que o principal reclamo de então era que cada universidade, em função de sua autonomia, fizesse a sua reforma (BASTOS 1980, p. 11). ${ }^{3}$

\section{b) A questão da institucionalização da pós-graduação}

Cursos de mestrado e doutorado foram criados nos inícios dos anos 1960, em várias instituições isoladas de ensino superior, de maneira que, em 1965, já existiam vinte mestrados e dez doutorados no país (PAOLI 1985, p. 37). ${ }^{4}$ Havia um leque de possibilidades em termos de experiências inovadoras, as quais foram bruscamente cerceadas ou decepadas a partir de 1964. Tal como se fez com a universidade, a pós-graduação também deveria obedecer a um modelo uniforme em todo o território nacional.

Em 1965, o Parecer 977/65, do conselheiro Newton Sucupira, em 20 atendimento a solicitação do Ministro da Educação ao Presidente do CFE, definiu de forma taxativa a natureza e os objetivos da pós-graduação em geral. Temos aí o chamado marco legal inicial da institucionalização da pós- graduação, conforme se lê no relatório do Grupo de Trabalho para a Reforma Universitária (Decreto-Lei 62.937 de 2 de julho de 1968). Passamos assim da discussão democrática de diretrizes e princípios às decisões autoritárias de cunho iluminista, da pluralidade de perspectivas, isto é, dos muitos futuros possíveis, à uniformização burocrática e centralizada.

A referência da institucionalização veio a ser a Lei da reforma universitária, de 1968, referida linhas acima. Na verdade, na legislação anterior do ensino superior, e na própria LDBEN, de 1961, a pós-graduação, quando mencionada, o é sempre em termos bastante genéricos. Queriam alguns, então, que cada Universidade definisse as características de seus cursos de pós-graduação (BASTOS 1980, p. 12-15). Todavia, a Lei da Reforma Universitária, de 1968, atribuiu ao CFE a competência para baixar normas para a organização da pós-graduação, o controle desta última por intermédio do credenciamento. Em 1969, o CFE aprovou o Parecer 77/69, do conselheiro Newton Sucupira, definindo as normas para esse credenciamento dos cursos de pós-graduação.

\footnotetext{
3 "A pós-graduação analisada sob os aspectos legais mereceu da Lei de Diretrizes e Bases da Educação Nacional (Lei 4024, de 20/12/1961) nova formulação conforme consta de seu artigo 69" (BASTOS 1980, p. 11).

4 "Esta liberdade de decisão não se referia apenas ao ensino pós-graduado, pois até então a universidade, enquanto um setor da universidade brasileira, conseguiu manter uma autonomia relativamente ampla" (PAOLI 1985 , p. 37, nota 21). Nesta nota o autor menciona vários outros trabalhos de sua autoria sobre a questão da institucionalização.
} 
Estabelecia-se assim, o modelo único em seus 18 artigos distribuídos ao longo de seis páginas (SCHWARTZMAN 1979, p. 298; FÁVERO 1991). ${ }^{5}$

A adoção, ou antes, a imposição de um modelo único de pós-graduação para todas as universidades brasileiras e institutos de pesquisa constituiu na prática o ápice de um processo de ocultamento em relação às reais possibilidades então existentes de implantação de experiências diversificadas e concorrentes entre si. Tal ocultamento veio a contaminar a própria memória dessa questão, levando ao aparecimento de uma história fortemente marcada pelo viés iluminista dominante à época da institucionalização. Desse apagamento das possibilidades da diferença surgiu o mito que sobrevive até hoje de uma pós-graduação uniforme como alguma coisa consensual e historicamente necessária. O controle político-ideológico sobre professores e alunos foi talvez somente a parte mais ostensiva e violenta dessa imposição de um controle burocrático autoritário sobre todas as atividades acadêmicas, inclusive a produção intelectual. É no mínimo curioso que até hoje, mais de meio século após, o modelo decretado pelo regime militar continue a pautar o dia a dia de nossos programas de pós-graduação cada vez mais submetidos ao controle de uma CAPES hipertrofiada.

\section{Alternâncias e interpenetrações de memória e história}

Passemos agora à tentativa de narrar propriamente os acontecimentos. Misturam-se a partir daqui memória e história. Nossas próprias lembranças conflitam ou corroboram, mas, sobretudo, complementam os dados documentais e bibliográficos. São muitas vivências e fatos, nem sempre fáceis de separar. Enfim, trata-se de uma narrativa muito pessoal, talvez mais testemunho que história propriamente dita, dada a nossa participação no próprio processo que queremos descrever.

\section{De volta às origens, ou quando tudo começou}

Dos meados dos anos 1950 aos dos anos 1960, isto é, de 1955 a 1964, misturam-se os nossos primeiros anos em Niterói, como professor, e a história da graduação em história, na Faculdade Fluminense de Filosofia e, depois, na nova universidade federal UFERJ, mais tarde UFF (VIEIRA s/d, p. 43; 50-55).

Começamos a trabalhar no curso de história quando ainda cursávamos o $4^{\circ}$ ano do curso de geografia e história da Faculdade Nacional de Filosofia da Universidade do Brasil, em 1955. No primeiro semestre deste ano fizemos algumas palestras, a convite da professora Eugênia Damasceno Vieira Prado, então à frente da cadeira de história moderna e contemporânea da Faculdade Fluminense de Filosofia, para a turma do $3^{\circ}$ ano da Faculdade Fluminense. Já

\footnotetext{
${ }_{5}^{5}$ Convém ainda salientar, como afirma Schwartzman (1979), que: "os novos programas de pós-graduação foram também prejudicados pelo clima político depois de 1968. Entre 1969 e 1970 várias dezenas dentre os mais talentosos cientistas brasileiros foram afastados compulsoriamente de suas posições de ensino e pesquisa, sendo levados, em muitos casos, a deixar o país... A ocorrência destas punições políticas no momento em que os novos programas de pós-graduação se criavam colocou-os sob justificável suspeita para grande parte da comunidade científica e universitária do país e fez com que muitos deles se vissem despojados de suas lideranças intelectuais quando elas seriam, supostamente, mais necessárias" (SCHWARTZMAN 1979, p. 298). Cf. FÁVERO 1991 e, da mesma autora, na série de estudos publicados pelo PROEDES / UFRJ, constam pelo menos cinco trabalhos interessantes sobre a universidade brasileira a partir de uma perspectiva crítica.
} 
no segundo semestre, aceitamos o lugar de assistente da professora Eugênia e começamos a lecionar regularmente (duas vezes por semana) na cadeira de história moderna e contemporânea.

Até o ano de 1960, quando se generalizou a discussão sobre a federalização, nosso trabalho na Faculdade Fluminense de Filosofia foi tranquilo, em colaboração com a professora Eugênia Prado e, a seguir, com o professor Hugo Weis, com quem já trabalhávamos na FNFi. Seguíamos em linhas gerais o planejamento já existente na cadeira de história moderna e contemporânea da FNFi, embora simplificado quanto às modalidades e conteúdos dos trabalhos discentes, uma vez que sabíamos das dificuldades de nossos alunos em termos de acesso à bibliografia mais especializada. A faculdade funcionava no prédio do Instituto de Educação e, depois, transferiu-se para as instalações da Escola Técnica Aurelino Leal, em frente ao Palácio do Ingá. Turmas pequenas, alunos atentos e muito estudiosos, presença da fiscalização federal através de um inspetor do MEC, tempos tranquilos enfim.

Apesar da atmosfera tranquila de então, "típica de Niterói", como se dizia, há muito os estudantes vinham se mobilizando, através da União Fluminense de Estudantes, no sentido de conseguir a fundação de uma universidade federal. 0 movimento acelerou-se a partir de 1958, com apoio do governo estadual, apoio que se intensificou, em 1959, com Roberto Silveira. A partir de 1960 a questão da federalização se converte em tema polêmico, antes e depois da assinatura da Lei 3848, de 18 de dezembro de 1960, pelo Presidente Juscelino Kubitschek, 22 criando a UFERJ.

O ano de 1961 marca o agravamento das disputas que iriam se prolongar até 1965, e foi também o ano da morte do governador Roberto Silveira e da renúncia do Presidente Jânio Quadros. A Lei 3848, de 18 de dezembro, previa aprovação do Estatuto da UFERJ pelo Poder Executivo, mas, ao mesmo tempo, dividia entre incorporadas e agregadas as instituições de ensino superior que deveriam integrar a nova universidade criando assim, na prática, dois grupos ou duas forças antagônicas. Vieram, então, os anos de lutas em prol da federalização das agregadas e dos conflitos em torno do cargo de reitor pelas facções em luta. No trabalho que escreveu sobre a história da UFF (VIEIRA s/d, p. 58-71) o professor José Ribas Vieira narra os pormenores desses conflitos de então, inclusive seus componentes políticos e suas relações com o processo mais amplo da política brasileira, de Jânio ao golpe militar de 1964 (VIEIRA $\mathrm{s} / \mathrm{d}, \mathrm{p}$. 74-77). Segundo Ribas, foram dois os principais momentos de crise: 1961 e 1963/1964, com a trégua da administração do reitor Paulo Gomes da Silva (1961-1963) e uma intervenção: em 12 de fevereiro de 1965 é nomeado o professor Raul Jobim Bittencourt para, na condição de reitor "pro-tempore", restabelecer a paz universitária. A universidade se organiza, constitui seu corpo de professores e funcionários, incorpora, finalmente, como hospital universitário, o Hospital Antônio Pedro. Finalmente, em 17 de julho de 1966, foi nomeado reitor o professor Manoel Barreto Netto (1966-1970). A UFF, como agora se denominava a antiga UFERJ, em função da Lei 4831 de 5 de novembro de 1965, entrava finalmente no caminho da normalidade institucional! 
Como docente da Faculdade Fluminense de Filosofia, fazíamos parte das chamadas agregadas. Todavia não participávamos praticamente dos debates e lutas então em andamento. Chegavam-nos notícias e comunicados, ora por intermédio do prof. Luiz Cesar Bittencourt Silva, nosso chefe de departamento, ora através do prof. Luiz de Castro Faria, titular de antropologia e pertencente ao Museu Nacional, ou do professor Durval Baptista Pereira, diretor da Faculdade de Filosofia. Acompanhávamos de longe, por assim dizer, os acontecimentos e todos respiramos aliviados quando, afinal, saiu o enquadramento dos professores e funcionários, em 1963. À testa da área de história moderna e contemporânea, começamos a reorganizar o respectivo quadro docente já que o prof. Hugo Weis assumira o lugar de titular de história da América. Não me lembro mais em que ano, saímos da Escola Técnica Aurelino Leal e fomos para o prédio recém-inaugurado da Faculdade de Filosofia, na rua Dr. Celestino, de onde, em pouco tempo, iríamos para o prédio da reitoria, na praia de Icaraí, onde o departamento de história funcionava no $3^{\circ}$ andar e as salas de aula ficavam nos fundos do teatro.

A partir dos acontecimentos de 31 de março de 1964, o ambiente tornou-se mais tenso e agitado no departamento de história. Procurávamos assegurar a normalidade da execução do programa de aulas e trabalhos da área de história moderna e contemporânea, mas vivíamos também os sobressaltos do movimento estudantil, em Niterói e no Rio de Janeiro, os rumores sobre proibição de livros, os boatos sobre a presença de espiões em nosso meio. Apesar de tudo, nosso trabalho era bem mais tranquilo e produtivo do que no Rio de Janeiro!

Curiosamente, porém, foi nessa mesma época que se tornou mais forte o prestígio da chamada história quantitativa (FALCON 1985, p. 11-12), o qual nos levou a uma reforma curricular destinada a adequar o nosso curso aos novos tempos, com a inclusão de várias disciplinas mais científicas: complementos de matemática, introdução à estatística e história econômica. ${ }^{6}$ Anos depois, no entanto, passada a maré quantitativista, fizemos nova reforma do currículo, deixando ficar apenas a história econômica geral e do Brasil.

Em 1967, foram discutidos e aprovados, pelo Conselho Universitário, o novo Estatuto e o novo Regimento da UFF, com base no que determinavam o Decreto-Lei número 53 de 18 de novembro de 1966, e o Decreto-Lei número 252 de 23 de fevereiro de 1967. Os docentes da UFF tiveram alguma participação nessa discussão cujo resultado foi a criação dos quatro Centros e a manutenção de várias das antigas unidades. A reforma provocou novos debates e descontentamentos. Em 1968, no clima de agitação de meados daquele ano, realizou-se o I Seminário de Professores e Alunos do ICHF, no qual foram discutidas inúmeras questões relativas aos departamentos de História, Ciências Sociais e Filosofia, tais como: corpo docente; biblioteca, regime de trabalho, extensão etc. Foi um momento

\footnotetext{
${ }_{6}$ Conforme analisamos em outro artigo, a moda ou febre da chamada história quantitativa, não foi um fenômeno limitado ao nosso departamento, na UFF. Teve impacto também na PUC-Rio e no IFCS/UFRJ, na área do Rio de Janeiro. Sua consagração talvez tenha sido o Colóquio realizado em Paris, em 1971, sob a direção de F. Mauro (FALCON 2000; 2011). Aliás, no nosso departamento, tal evento custou-nos a demissão da professora Maria Bárbara Levy, que compareceu ao Colóquio e ficou mais de 30 dias ausente de suas funções, justificando assim, pelo menos foi o argumento utilizado, seu afastamento.
} 
importante, significativo mesmo, mas acabou sendo apenas o prelúdio às medidas punitivas resultantes do AI 5 de dezembro de 1968.

De 1964 a 1968, fomos contemporâneos de uma época agitada, não raro confusa, durante a qual conviveram acontecimentos os mais diversos: a presidência do marechal Castelo Branco e as pressões dos oficiais da chamada linha dura; o Ato Institucional número 2, em outubro de 1965; a posse do general Arthur da Costa e Silva na presidência da República, em 1967; a retomada do ciclo de agitações estudantis com as grandes passeatas, de 1967/1968; os festivais da canção e suas músicas de protesto; a nova investida da linha dura e o AI 5, em dezembro de 1968.

O Plano de Reestruturação da UFF, encaminhado à Câmara de Ensino Superior do CFE, sofreu inúmeras críticas e modificações, daí resultando o texto final sobre a reestruturação, aprovado pelo Decreto 62.414 de 15 de março de 1968. O Estatuto e o Regimento Geral da UFF foram aprovados pelo CFE através do Parecer 696 de 05/09/69. Em 1974, um novo Regimento Geral foi aprovado pelo CFE, através do Parecer 4111/74. Mencionamos a existência destes textos porque a sua consulta mais atenta permite ao leitor verificar o quanto era ainda escassa a preocupação com a pós-graduação, em geral mencionada em termos bastante genéricos, mas raramente concretamente explicitada.

Bem, nos começos de abril de 1969, já em plena vigência do AI 5, embarcamos para Lisboa, para uma bolsa de estudos concedida pelo governo de Portugal através do Instituto para a Alta Cultura. Íamos realizar as pesquisas 24 necessárias ao nosso projeto de tese sobre a Era Pombalina. De lá, na loja da Varig, buscávamos notícias sobre o Brasil em jornais e revistas brasileiros. Foi assim que ficamos sabendo das aposentadorias de muitos dos nossos colegas das universidades federais.

Retornamos em novembro/dezembro de 1969. O departamento de história integrava agora o Instituto de Filosofia e Ciências Sociais, subordinado ao Centro de Estudos Gerais. Já não habitávamos mais o prédio da reitoria, pois tínhamos sido transferidos para a rua Lara Villela, nas antigas dependências do Colégio Bittencourt Silva. Ali ficaríamos até 1979, quando o ICHF se transferiu para um prédio novo, recém-inaugurado, no campus do Valonguinho. Nesse ano, aliás, o departamento de história patrocinou o Simpósio Nacional da ANPUH, um evento dos mais concorridos e de importância capital para os rumos da entidade, tendo-se em vista as discussões e resoluções que foram tomadas durante sua Assembleia Geral.

Os anos 1970, ou os "inesquecíveis anos de chumbo"

Em setembro de 1970, a profa. Aidyl de Carvalho Preis, diretora do Instituto de Filosofia e Ciências Sociais, constituiu uma comissão destinada a estudar "a viabilidade da implantação da pós-graduação", no Instituto em geral e no departamento de história em particular. Presidimos a citada Comissão e as discussões sobre as perspectivas e características de uma futura pós- graduação em história em nível de mestrado. O parecer final da Comissão assinalou "a conveniência de ser dada prioridade à implantação do curso de 
mestrado em história". Foi então constituída, no âmbito do departamento de história, uma comissão de pós-graduação com a tarefa de "planejar e orientar a execução de todas as providências necessárias à implantação do respectivo curso de mestrado". O projeto preliminar foi apresentado em julho de 1971 ao departamento, quando foi aprovado o direito de matrícula no futuro curso para os docentes do Departamento sem exigência de provas de seleção, uma decisão bastante lógica apesar de algumas vozes discordantes.

Assim, o projeto do curso de pós-graduação em história foi aprovado em setembro de 1971 pela COMPEG, e, a seguir, pela Resolução 80/76 do Conselho Universitário, mas apenas em 25/08/76. Estava previsto que seria oferecido, inicialmente, um curso de aperfeiçoamento, devendo o curso de mestrado iniciar-se em 1973 e o doutorado em 1975. Definiram-se então, como áreas de concentração, a história econômico-social e a história político-social, assim como a exigência de cursos de historiografia e metodologia. O primeiro Edital foi publicado em outubro e a primeira seleção realizou-se em novembro de 1971. Logo depois, iniciou-se o primeiro Curso para Graduados - história econômica do Brasil, lecionado pela profa. dra. Nícia Vilela Luz, da USP. A seguir, foi oferecido o curso da profa. dra. Adeline Daumard, sobre demografia histórica e, já no segundo semestre de 1972, um curso do prof. dr. Pedro Freire Ribeiro (CORRÊA 2001, p. 40-42).

A partir do segundo semestre de 1972, foram contratados os professores doutores Richard Graham e Stanley E. Hilton, os quais permaneceram no programa até julho de 1974. Era o início da fase do curso de pós-graduação em história marcada pela forte participação dos chamados brazilianistas, norte-americanos em sua maioria. Os motivos dessa opção por professores norte-americanos e não por professores da USP, por exemplo, têm a ver, segundo a professora Aidyl Preis, com uma oferta da CAPES no sentido de financiar sua contratação. A presença dos brazilianistas suscitou uma querela nos meios acadêmicos, com manifestações pró e contra suas pesquisas e orientações. O prof. José Honório Rodrigues, por exemplo, embora amigo pessoal de muitos desses professores norte-americanos, criticou em diversas ocasiões as diferenças de tratamento por parte das instituições brasileiras (arquivos e bibliotecas) aos pesquisadores conforme fossem eles estrangeiros ou brasileiros - acesso amplo aos primeiros e restrições não raro severas aos segundos (CORRÊA 2001, p. 48-52).

A presença desses docentes teve como consequência uma rediscussão das áreas de concentração existentes, a qual se concluiu pela adoção da história do Brasil e da história da América como áreas de concentração do programa. Um enunciado tão singelo como este oculta na verdade uma das questões mais polêmicas presentes nas memórias e histórias do programa. Em sua dissertação intitulada "De que lugares fala essa história", Maria Amélia Ayd Corrêa recorre a diversas entrevistas assim como outras fontes para analisar quais os motivos que levaram à substituição de história econômico-social e história político-social, como áreas de concentração, por história do Brasil e história da América (FALCON 2012a, p. 12-13). Tal como afirmamos em nosso texto, que consta da publicação "Memória dos Cursos de Pós-Graduação - Mestrado em História" 
(CORRÊA 2001, p. 33-37), a autora, Ayd Corrêa, também afirma que só a partir do segundo semestre de 1972 foram implementadas as áreas de América e Brasil. Variam as explicações apresentadas para tal mudança embora, em sua maioria (FALCON 2012a, p. 14) concordem com a nossa afirmação inicial: a mudança se deu, de uma forma ou de outra, em decorrência da chegada dos brazilianistas ao programa, isto é, do ajustamento deste último às características profissionais e preferências temáticas dos recém-chegados.

Participaram posteriormente do programa outros brazilianistas como Bailey W. Diffie (até abril de 1974), Michael Morris (até dezembro de 1974) e Richard M. Morse, entre diversos outros, cujos nomes se acham relacionados na publicação Memória dos Cursos de Pós-Graduação, editada pela EDUFF/PROPP, em 1985 (FALCON; CARVALHO; FERREIRA 2012c).

Muito se discutiu à época, o papel proeminente assumido pelos docentes norte-americanos no âmbito do programa de pós-graduação em história da UFF. Opiniões divergentes, convém frisar, pró e contra. Querendo ou não, no entanto, essa foi a maneira de implementar o programa com rapidez. Não tínhamos docentes com a titulação necessária, nem era fácil encontrá-los. A professora Ismênia de Lima Martins foi das primeiras a doutorar-se (na USP) e logo passou a integrar o corpo docente do programa. Logo vieram o prof. dr. Pedro Demo e os docentes já veteranos, como José Honório Rodrigues, Luiz de Castro Faria, Arthur Cezar Ferreira Reis, Nilo Bernardes e Lysia C. Bernardes, Pedro Freire Ribeiro, assim como o professor dr. Victor Vincent Valla.

Em 1974 foram defendidas e aprovadas as oito primeiras dissertações de mestrado: três orientadas pelo prof. dr. Stanley Hilton e seis pelo prof. dr. Richard Graham, o qual também orientou e organizou uma primeira publicação do programa: Ensaios sobre a política e a economia da província fluminense no século XIX. Em 1975 foi aprovada uma dissertação, seguida de outras seis em 1976, quase todas resultantes de projetos elaborados à época dos professores Graham e Hilton. Foi também em 1975 que o programa recebeu da CAPES suas cinco primeiras bolsas

Em 1975, havia diversas linhas de pesquisa: história da América Latina, história dos Estados Unidos, história do Brasil e história do México. Tal foi a consequência da definição das linhas de pesquisa e das áreas de concentração de acordo com as preferências, interesses ou inclinações intelectuais de alguns docentes. Justamente por tal motivo nos afastamos do programa em 1973 e a ele só retornamos em 1976, pois, como tínhamos proposto, deveríamos pensar em termos menos paroquiais, ou mais modernos, como história econômica, história política e história social. No intervalo em que estivemos ausentes, aproveitamos para terminar a nossa tese sobre a Época Pombalina, defendida em concurso público de livre-docência em 1976, na própria UFF.

O período de 1975/1976 até 1978/1979 trouxe alguns avanços e uma progressiva estabilização com o aumento do quadro de docentes nacionais, apesar da presença ainda marcante de brazilianistas. Retirou-se o professor Pedro Demo, entrando em seu lugar a professora Salma T. Muchail. Foi mantida a circulação dos brazilianistas, que vinham com prazos variáveis de permanência: 
Francis W. Morton, Ronny L. Seckinger, Roy A. Glasgow e também, um pouco mais tarde: Steven C. Topik e Robert Slenes.

Em abril de 1977 foi aprovado o "Regulamento Específico do Curso de Mestrado em História", iniciando-se o processo de credenciamento, afinal concedido através do Parecer 104/78 do Conselho Federal de Educação. Ficavam mantidas as áreas de concentração em história do Brasil e história da América e o corpo docente estava então constituído pelos professores doutores: Aidyl de Carvalho Preis (coordenadora), Arthur Cezar Ferreira Reis, Francis William Orde Morton, Francisco José Calazans Falcon, Ismênia de Lima Martins, José Honório Rodrigues, Luiz de Castro Faria, Nilo Bernardes, Pedro Freire Ribeiro, Ronny Lery Seckinger, Roy Arthur Glasgow, Rui de Carvalho B. Lourenço Filho, Salma Tannus Muchail, Victor Vincent Valla, Luiz Cezar Aguiar Bittencourt Silva e Maximiano de Carvalho e Silva. No ano de 1977 foram aprovadas quatro dissertações e, no ano seguinte, mais dezenove.

Muitas e muitas vezes nos perguntamos, ou fomos indagados, sobre como vivemos, ou sobrevivemos ao longo desses anos 1970. Diante do clima de terror que se criou no IFCS/UFRJ, sobretudo no departamento de história, e ao qual já fizemos referência em trabalho sobre a história da pós-graduação em história no Largo de São Francisco (FALCON; CARVALHO; FERREIRA 2012c), criou-se o mito de que "em Niterói teríamos desfrutado de uma tranquilidade quase total [...]". Bem, nem tanto ao mar, nem tanto à terra. Os ambientes eram diferentes, assim como as condições de trabalho e a liberdade de lecionar e pensar. Mas tivemos também nossos fantasmas. Por sorte, porém, tivemos pessoas cujo caráter se tornou uma barreira às tentativas de incursões dos agentes da intolerância. Várias pessoas, na verdade, mas, em primeiro lugar, aquele que foi uma espécie de nosso patrono: o professor Luiz Cezar Bittencourt Silva, titular de história antiga e medieval. Houve espionagem de algumas aulas, boatos atemorizadores, perseguição contra alguns professores, inclusive o funcionamento de um esdrúxulo critério de "ficha política limpa" para o professor poder vir a ser contratado. Tivemos também alunos perseguidos e alguns até desaparecidos. Eram tempos difíceis, mas, apesar de tudo isso, seguimos em frente!

\section{O período das transformações que marcaram a reformulação do curso de mestrado e a estruturação do curso de doutorado}

Denominamos assim, período das transformações, àqueles anos, no final da década de 1970 e começos da década de 1980, nos quais a rotina de nossos trabalhos e sobretudo a tranquilidade das relações docentes e discentes foram seriamente abaladas pela entrada de alguns estranhos no ninho do colegiado do programa. Para isto concorreu bastante a anistia ampla, geral e irrestrita, aprovada em 1979, mas não só. A primeira perturbação deu-se antes da anistia: a contratação do prof. dr. Ciro Flamarion Santana Cardoso para o corpo docente do mestrado. O professor Ciro representou um sopro de novas questões, demanda de novos critérios, e, sobretudo, exigência de rigor teórico-metodológico (FALCON 2012b). Encantou aos alunos, mas feriu velhas susceptibilidades. Há muito sentíamos que o mestrado carecia de maior 
embasamento teórico e considerávamos preocupantes certas afirmações de alguns dos brazilianistas que nos diziam não dar a menor importância a questões teóricas. O primeiro setor a se sentir melindrado foi o de história da América, diante das críticas de Ciro Flamarion. Em 1979 entraram para o corpo docente as professoras doutoras Maria Yedda Leite Linhares, Eulalia Maria Lahmeyer Lobo, Maria Bárbara Levy e Margarida de Sousa Neves, assim como Pedro Celso Uchoa Cavalcanti Melo. O prof. dr. Nilo Bernardes, já pertencente ao programa, destacou-se nesta nova fase pelas propostas inovadoras e até certo ponto audaciosas, como, por exemplo, a criação da figura do co-orientador de dissertação, uma proposta que irritou profundamente os representantes da velha guarda. Outra proposta polêmica, parcialmente posta em prática, foi a de que os docentes, ou alguns dentre eles, assistissem às sessões de qualificação dos mestrandos. Os descontentes acabaram por demitir-se do programa.

A partir de 1978/1979 a política que visava obter uma estabilidade maior para o corpo docente, traduziu-se no aumento do percentual de professores permanentes, enquanto declinava bastante o percentual dos professores visitantes. A médio e longo prazos tal tendência só poderia intensificar-se em função da obtenção de titulação de professores pertencentes aos quadros do departamento de história. Por sinal, foi durante os anos iniciais da década de 1980 que se conseguiu equacionar, afinal, a antiga questão da separação ou distanciamento entre o programa e o departamento, situação funcional de alguns docentes da pós- graduação, relações com o ensino de graduação. Aos poucos, não sem algumas resistências, firmou-se o princípio da obrigatoriedade de lecionar na pós-graduação e também na graduação.

Havia também alguns professores visitantes, alguns deles vindos em função de convênios, como o assinado com a Universidade de Toulouse-Le Mirail, chamado convênio CAPES-COFECUB, o qual nos trouxe o excelente mestre Bartolomé Bennassar; o convênio com a Fundação Fullbright, que propiciou a vinda, entre outros do prof. Warren Dean; e o com convênio firmado com a Universidade de Costa Rica.

Como subcoordenador da pós-graduação e, a partir de 1982, como seu Coordenador, presidimos a muitas das reuniões do colegiado, participando de suas discussões. Presenciamos a discussões acaloradas, choques de posições inconciliáveis, conflitos pessoais, mas creio que conseguimos levar o barco adiante, apesar de tudo. Apesar de todas as divergências havia no colegiado, salvo algumas poucas exceções, o forte desejo de contribuir para elevar o nível do programa, obter melhores resultados dos alunos, criar condições reais para o futuro doutorado.

Além de questões respeitantes ao necessário rigor das orientações de trabalhos finais, entraram em pauta exigências da CAPES e do CNPq quanto à definição mais precisa de nossas linhas de pesquisa. As discussões arrastaram-se por mais de dois anos e no seu curso o debate foi se tornando cada vez mais abrangente, compreendendo práticas docentes, sistemas de avaliação, áreas de concentração, relações com o ensino de graduação. De fato, era a própria reestruturação do curso que estava em pauta. 
Uma das primeiras decisões foi a de abolir as barreiras até então existentes entre história do Brasil e história da América tendo em vista três aspectos: a escolha do tema de dissertação, a seleção para ingresso no programa, a matrícula nos cursos obrigatórios das áreas de concentração. Por outro lado, em 1980, primeiro semestre, foram fixadas as seguintes linhas de pesquisa: Escravidão e Abolição; Camadas Populares; História Regional; História das Ideias. Em 19821983, após novas reuniões e debates, houve uma reformulação simultânea de áreas de concentração e linhas de pesquisa, unificando-as, passando-se então ao modelo que perdurou por mais de uma década: História Social e Econômica da Agricultura; História Social da Industrialização e da Urbanização; História Social das Ideias. Deixou-se também mais ou menos implícito que o conceito de regional, referindo-se ao espaço fluminense constituiria preocupação prioritária de todos os pesquisadores.

Em outubro de 1982 começou o processo de recredenciamento do programa, que foi concluído com o Parecer 230/83 do CFE, plenamente favorável, de 6 de maio de 1983. Vale notar aqui, talvez como mera curiosidade, que esse Parecer do CFE menciona como linhas de pesquisa do mestrado: Escravidão e Abolição na América Latina e no Caribe (séculos XVIII e XIX); Industrialização, Operariado e Camadas Populares no Rio de Janeiro (séculos XIX e XX); História Social das Ideias no Brasil (séculos XIX e XX). Deve-se tal fato à circunstância de que por ocasião da visita da comissão da CAPES, em outubro de 1982, o colegiado do programa ainda não havia concluído os debates para a reformulação das áreas de concentração e das linhas de pesquisa.

Em 1982 foi encaminhado à FINEP um projeto a ser desenvolvido pelo programa de pós-graduação cujo título era: "Cidade e campo no complexo regional do Rio de Janeiro", composto de três subprojetos/subprogramas: O modelo de estagnação e a problemática da decadência - o Rio de Janeiro (Província - Estado): 1850 - 1950, coordenado pelos professores doutores Maria Yedda Leite Linhares e Robert W. Slenes; Processos industrializantes, condições de vida e movimentos operários (fins do século XIX - década de 1930), coordenado pelas professoras doutoras Eulália Maria Lahmeyer Lobo e Ismênia de Lima Martins; e Análise de discursos e suas ideologias na transição do trabalho escravo para o trabalho livre, coordenado pelo professor doutor Francisco José Calazans Falcon. Assinado em outubro de 1983, por vinte e quatro meses, o projeto iniciou-se em 1984 e foi concluído em 1986, produzindo diversos trabalhos sobre o período de 1870 a 1945, mas com a exclusão, por motivos financeiros, do subprojeto relativo à análise de discursos. Uma segunda etapa, ou novo projeto FINEP, iniciou-se em 1987 (segundo semestre), mas foi prejudicada pela crise de recursos daquela Agência.

Uma vez concluída a reestruturação do curso de mestrado, o colegiado do curso passou a discutir e planejar a estrutura do futuro curso de doutorado, cujas grandes linhas foram aprovadas no final de 1983. Tratava-se de um projeto estreitamente articulado àquele já aprovado para o mestrado.

As mudanças aprovadas em 1982 buscavam aproximar ao máximo as áreas de concentração das linhas de pesquisa, uma velha reivindicação nossa e 
do corpo docente em geral. O programa tendia a identificar-se, cada vez mais, como sendo de história social, com as seguintes áreas de concentração: história econômica e social da agricultura, história da urbanização e da industrialização, e história social das ideias. As linhas de pesquisa correspondentes eram assim denominadas: história social da agricultura ou, simplesmente, história agrária, história social da industrialização e da urbanização e história social das ideias. Numa época em que tanto se debatiam os conceitos de área de concentração e de linha de pesquisa, o colegiado do programa de pós-graduação em história da UFF optou por ultrapassar tal discussão e fazer valer, aí sim, em termos metodológicos, o corte regional, o compromisso com a região fluminense, além de fazer da referência à historia social o seu referencial teórico mais geral. Aos poucos o programa marchava rumo a um objetivo cada vez mais claro: fazer da história social a sua verdadeira área de concentração, em associação com uma concepção de algo assim como história-total.

Em dezembro de 1983 deixamos a coordenação do programa de pós- graduação a fim de realizarmos em Lisboa o estágio de pós-doutoramento aprovado pela CAPES, por um ano. A professora dra. Ismênia de Lima Martins assumiu nosso posto e tratou de providenciar, em 1984, o pedido de autorização para o início do curso de doutorado, junto às instâncias superiores da UFF e à CAPES. A autorização veio em 21 de novembro de 1984 e a primeira seleção teve lugar em janeiro de 1985, quando nós já havíamos retornado e reassumido a coordenação do programa (CORRÊA 2001). A renovação do credenciamento do 30 curso de mestrado e do credenciamento do curso de doutorado foi aprovada em 1988. A esta altura, já haviam sido aprovadas diversas modificações curriculares, a começar pela implantação dos setores temáticos, em 1987, tendo em vista principalmente as especificidades da formação nas áreas de história antiga e história medieval. O outro setor temático então criado foi o de história moderna e contemporânea.

Em sua "Introdução ao catálogo de teses e dissertações - 1974-1995", do programa de pós-graduação em história - UFF, a professora dra. Vânia Leite Fróes apresenta um breve resumo da evolução histórica desse programa, especialmente as características que marcaram as trajetórias das três linhas de pesquisa definidas em 1982. A autora chama atenção para o fato de que a criação das áreas temáticas, em 1988, não eliminou essas linhas de pesquisa, pois, pelo contrário foram elas estendidas à área de história antiga e medieval (FRÓES 1996). Tampouco a reforma curricular de 1991 veio a alterá-las. Uma comissão, nomeada pelo colegiado do programa, começou a estudar, em 1992, a pertinência das linhas de pesquisa então existentes.

Em 1994, houve a terceira renovação do credenciamento do curso de mestrado, e a segunda do curso de doutorado, sendo mantidas, de uma maneira geral, as áreas de concentração e as linhas de pesquisa. Mudanças maiores ocorreram a partir de 1997, quando foram definidas como linhas de pesquisa: História Cultural, Economia e Sociedade, Poder e Política, e História Regional. Ao mesmo tempo, manteve-se a História Social como área de concentração. 


\section{Algumas informações finais}

Devemos esclarecer ao leitor que as informações contidas na parte final do presente trabalho, um tanto fragmentárias, é justo reconhecê-lo, foram pinçadas aqui e ali em diversas fontes, pois, para nós a história termina em 1990, quando, ao deixar a Pró-Reitoria de Pesquisa e Pós-Graduação, nos aposentamos na UFF. A rigor, aliás, vivenciamos mesmo o programa somente até os meados de 1986.

A sistematização das informações sobre dissertações, teses, e pesquisas, consta principalmente das seguintes publicações: 1) Memória dos cursos de pós- graduação - mestrado de história, publicado pela PROPP/EDUFF, 1985 - onde estão relacionadas 91 dissertações de mestrado, de 1974 a 1984; 2) Programa de pós-graduação em história, UFF. Catálogo de teses e dissertações - 19741995, no qual estão relacionados 267 trabalhos, inclusive 22 teses de doutorado; 3) O vol. 3 da obra intitulada Produção histórica no Brasil, coordenada por Maria Helena R. Capelato, no qual estão incluídas as dissertações e teses defendidas entre 1985 e 1994 na UFF. A produção cientifica docente foi incluída em dois catálogos, um de 1986-1988, e outro, de 1990.

\section{Referências bibliográficas}

ARÓSTEGUI, Julio. A pesquisa histórica. Teoria e método. Bauru: Edusc, 2006.

BASTOS, Jésus de Alvarenga. Pós-graduação no Brasil: institucionalização e situação atual. Niterói: UFF / CESA / Faculdade de Educação, 1980.

CORRÊA, Maria Amélia Ayd. De que lugares fala essa história? As matrizes teórico-metodológicas na produção discente do Programa de Pós-Graduação Stricto Sensu em História da UFF (1989 - 1996). Rio de Janeiro: PPGHIS / UFRJ, Dissertação de Mestrado em História Social, 2001.

CUNHA, Luiz Antônio. A universidade temporã. Rio de Janeiro: Civilização Brasileira, 1980.

FALCON, Francisco J. Calazans. Histórico do curso. In: Memória dos cursos de pós-graduação: mestrado em história. Niterói: PROPP / UFF / EDUFF, 1985.

A identidade do historiador. Estudos Históricos, Rio de Janeiro, FGV, vol. IX, número 17, 1996, p. 7-30.

. Depoimento - a pós-graduação em história. Maracanan, IFCH/UERJ, ano 1 , número $1,1999 / 2000$, p. 118-133.

. L'historiographie brésilienne contemporaine (1958-1969). In: CROUZET, François; ROLLAND, Denis (dir.). Pour I'histoire du Brésil. Mélanges offerts à K. de Queirós Mattoso. Paris: L'Harmattan, 2000, p. 93-108.

- Historiografia e ensino de história em tempos de crise - 1959/60 1968/69. In: MUNTEAL FILHO, Oswaldo; FREIXO, Adriano de Freixo e FREITAS, Jacqueline Ventapane (orgs.). Tempo negro, temperatura 
sufocante. Estado e sociedade no Brasil do AI-5. Rio de Janeiro: PUCRio/Contraponto, 2008, p. 45-40.

. A historiografia fluminense a partir dos anos 1950/60: algumas direções

e pesquisas. In: GLEZER, Raquel (org.). Do passado para o futuro: edição comemorativa dos 50 anos da ANPUH. São Paulo: Contexto, 2011, p. 13-68.

Memória e história. A fundação da ANPUH -Conferência, em julho de 2011. Anais do XXVI Simpósio Nacional de História (Anais Eletrônicos), 2012a, p.1-18.

- Ciro Flamarion Santana Cardoso: uma memória em vários tempos. In: ARAÚJO, Sônia Regina Rebel de; LIMA, Alexandre Carneiro Cerqueira (orgs.). Professor Ciro Flamarion Cardoso: um combatente pela história. Rio de Janeiro: Vício de Leitura, 2012b, p. 29-42.

; CARVALHO, José Murilo de; FERREIRA, Marieta de Moraes. Reflexões sobre o programa de pós-graduação em história social - trinta anos, Topoi, Rio de Janeiro, v. 13, n. 25, p. 6-24, julho / Dezembro, 2012c. Disponível em: www.revistatopoi.org.

FÁVERO, Maria de Lourdes. Da universidade modernizada à universidade disciplinada: Atcon e Meira Mattos. São Paulo: Cortez; Autores Associados, 1991.

32 IGLÉSIAS, Francisco. Comentários à introdução monográfica sobre a área de história, de Alice Canabrava. Anais do I Encontro de Estudos Brasileiros. São Paulo: IEB, v. II, 1972, p. 21- 34.

Os historiadores do Brasil: capítulos de historiografia brasileira. Rio de Janeiro: Nova Fronteira; Belo Horizonte: UFMG, IPEA, 2000.

LAPA, José Roberto do Amaral. A história em questão: historiografia brasileira contemporânea. Petrópolis: Vozes, 1976, p. 13-96.

OLIVEIRA, Antonio José Barbosa de (org.). Universidade e lugares de memória. Rio de Janeiro: UFRJ/FCC/SIBI, 2008.

PAIM, Antônio. A UDF e a ideia de universidade. Rio de Janeiro: Tempo Brasileiro, 1981.

PAOLI, Niuvenius Junqueira. Para repensar a universidade e a pós-graduação. Campinas: UNICAMP, 1985.

SCHWARTZMAN, Simon. Formação da comunidade cientifica no Brasil. São Paulo: Editora Nacional/FINEP, 1979.

VIEIRA, José Ribas. A Universidade Federal Fluminense: de um projeto adiado à sua consolidação institucional. Niterói: UFF / CEUFF / PROAC, s.d.

VILAR, Pierre. Iniciación al vocabulario del análisis histórico. Barcelona: Crítica, 1980. 